\title{
Talent policy satisfaction measurement based on policy experience a survey of China-ASEAN talents
}

\author{
Tang Shi ${ }^{1}$ \\ ${ }^{1}$ School of Public Administration, Sichuan University, SCU, Chengdu, China
}

\begin{abstract}
Talent resources in the 21 st century have become an important factor to promote social progress and economic growth, especially the advent of the Internet and information age has put forward higher requirements for the formulation of talent policy. With the further development of China and ASEAN countries in various fields, talent cooperation has become an important strategy. Based on the personal experience of talent policy from a micro perspective, this study identifies the satisfaction of talent policy including three dimensions of policy content satisfaction, policy implementation process satisfaction and policy implementation effect satisfaction, and combines the practice of talent policy in the world in recent years to form 12 indicators affecting talent policy satisfaction, and establishes a China-ASEAN talent policy satisfaction evaluation model. The research shows that China-ASEAN talents are generally satisfied with the current talent policy, but there is still the possibility of policy improvement, especially in optimizing the content of talent policy and improving talent service.
\end{abstract}

\section{INTRODUCTION}

Talent is the most powerful productive force in the $21 \mathrm{st}$ century and the core resource of scientific development. Talent does not have the national boundary. With the development of the Internet, talent policy is facing both opportunities and challenges. Especially with the development of China's Belt and Road, China and ASEAN countries follow the goal of win-win cooperation and determine the direction of common development of industries, such as agriculture, trade, tourism, investment, information and communication, public management, logistics, exhibition and so on, which makes the two sides on the relevant industries in the field of high-quality human resources increasing demand, talent exchange and cooperation has been mentioned to a new level of strategic cooperation.

In order to make full use of human resources, China and ASEAN have made achievements in the development of human resources in recent years. China has established the China-ASEAN Cooperation Fund and trained thousands of professionals in more than a dozen fields, including economy and trade, finance, agricultural biology and marine science and technology. At the same time, the Chinese government has set up special funds for regional cooperation in Asia to support the participation of relevant Chinese departments in regional cooperation, especially with ASEAN. At present, China has signed mutual recognition agreements with Thailand, Vietnam, the Philippines, Malaysia and Indonesia, and has implemented the Silk Road Study Promotion Program and the Education Assistance Program. In November 2007, the Guangxi base of China-ASEAN talent resource development cooperation was unveiled, which is the first base of China-ASEAN talent resource development cooperation. In 2018, Nanning, Guangxi, launched a regional international talent highland action plan for ASEAN.

It can be seen that China and ASEAN have made great efforts to promote the cooperative development of human resources. With the advent of the Internet information age, the Internet has provided convenience for the dissemination and consultation of talent policy, provided the possibility for the management of talent information big data, and provided a platform for global talent sharing, but at the same time, the development of modern information has also caused the brain drain under the information explosion, the failure of talent management of traditional government organizations and so on. Facing the coming of the Internet age, how to update the talent policy of Internet thinking is very important. The traditional talent management, talent incentive and talent retention need to be changed urgently. Internet thinking emphasizes the user-centered remodeling of the enterprise system, talent policy Internet thinking emphasizes the needs and satisfaction of talent. Facing the fierce situation of global talent competition, how to optimize talent policy, how to use the advantages of China-ASEAN cooperation to attract talent, how to realize the specialization, informatization, industrialization and internationalization of talent development has become the research focus of talent work practice. Based on the micro-policy 
experience perspective and taking China-ASEAN talents as the research object, this study attempts to study the talent policy satisfaction of this representative group, thus promoting the optimization of talent policy and the development of talent resources, providing talent power support for win-win cooperation between China and ASEAN countries, and constructing a talent policy satisfaction scale to provide a theoretical model for future evaluation.

\section{HOW TO MEASURE POLICY SATISFACTION}

The study of satisfaction began with customer satisfaction in the business world. Richard first proposed the concept of "customer satisfaction" [1]. On this basis, Oliver puts forward a representative theory of customer expectation difference. The core of this theory is that differences in expectations are the key factors affecting public satisfaction. Public satisfaction is higher when subjective feelings are higher than or equal to expectations, and lower when subjective feelings are lower than expectations. Based on it, Oliver defines satisfaction as a collection of emotions and feelings that are generated by the customer's expectations and experiences after the purchase of a product or service ${ }^{[2]}$. Due to the subjective nature of customer satisfaction and the difficulty of measuring, the Swedish Customer Satisfaction Barometer was proposed [3]. On the basis of it, Dick proposed America Customer Satisfaction Model (ACSI) and has become the most widely used national satisfaction index model ${ }^{[4]}$. With the successful application of customer satisfaction in the business field, the public sector began to introduce public service satisfaction into the government's public service performance evaluation. Since the 1980s, the new public management movement has emphasized the government's sense of service and performance management, treating citizens as "customers". Since then, public sector customer satisfaction model has been created.

In order to build the talent policy satisfaction model, we should first define what is talent. Talent is the person with certain professional knowledge or specialized skills and contribute to society. Talent policy is a concrete measure formulated by the government, enterprises and other organizations in order to attract talents, cultivate talents and retain talents. It can be seen that talents are the most direct service object of talent policy, but also the most important consumers of public goods and public services, their evaluation of the quality and service of public policy can't be ignored. The policy service object examines the policy satisfaction, so as to realize the value judgment of the policy implementation. Understanding citizens' satisfaction with the implementation of government policy can help provide empirical evidence for the formulation and implementation of government public policy. Based on this, we can conclude that talent policy satisfaction is the degree of recognition and acceptance of talent policy in the process of policy formulation and implementation. From the policy cycle, talent policy satisfaction includes both talent satisfaction with policy formulation and talent satisfaction with policy implementation and effectiveness. Therefore, the talent policy satisfaction model of this study includes the content satisfaction of talent policy content in the policymaking stage, the satisfaction of the policy implementation process in the policy implementation stage, and the satisfaction of the policy effect in the policy landing stage.

The talent policy satisfaction model, like other satisfaction models, should be constructed on the basis of the theory of customer expectation difference. Therefore, it is very important to explore the expectations of talents on talent policy from the perspective of talents. Holland argues that the key to an effective talent policy is to understand the demand for talent ${ }^{[5]}$. The demand for talents can be distinguished into welfare needs and developmental needs, the former refers to the demand for work environment, life security, family stability and so on the latter refers to the need to promote talents to develop their talents and potential, stimulate passion for work and so on. Therefore, this study summarizes the satisfaction factors from the perspective of talent into the following four aspects. First, job opportunities are important. People tend to make large and expensive investments in their own development, so they want to find the best return on their human investment. The opportunities they seek are not just financial, but also the possibility of achieving personal and professional goals. This may often depend on factors such as capital, infrastructure, or the presence of other talent in the same field ${ }^{[6]}$. Second, we should think about the sense of belonging to organization or city. Job opportunities are no longer the only determining factor in a knowledge worker's decision to settle in a country or city ${ }^{[7]}$. A sense of belonging not only retains talent, but also keeps them in high-performing jobs ${ }^{[8]}$. Third, talent will think about the environment of the country in which they are located. Factors such as affordable childcare and high-quality schools are important for those considering long-term residence and family, as are urban social patterns, lifestyles and quality of life, social inclusion and safety ${ }^{[9]}$. Fourth, the role played by the family or social network is immeasurable when choosing a career. Harvey found that social networks have a huge influence when British and Indian scientists consider whether to immigrate to the United States, and their immediate family members play a particularly important role ${ }^{[10]}$.

Based on the above research results, this study will create the three dimensions of policy content satisfaction, policy implementation process satisfaction and policy implementation effect satisfaction according to the policy cycle theory. At the same time, the talent policy satisfaction model also included 12 variables such as welfare treatment policy, life security policy, career policy, social relations policy, policy publicity, procedures, service attitude of the operating institution, service capability, policy awareness, policy benefit, policy dependence, policy implementation, as shown in the Fig. 1 . 


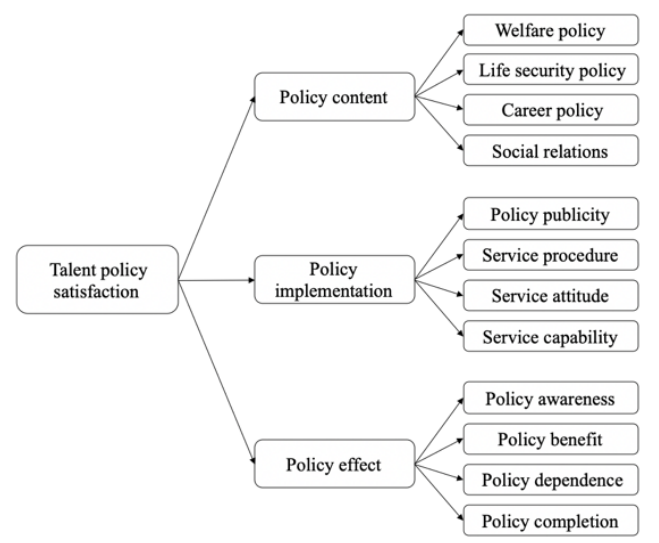

Figure 1. Talent policy satisfaction measurement model.

\section{RESULTS}

This survey was sent online. We chose talents who are promoting industrial cooperation between China and ASEAN countries as the research objects. The study eventually collected 170 valid questionnaires. Our survey used the Likert scale, the questionnaire divided satisfaction into five levels of satisfaction, we asked the participants to rate their feelings towards the talent policy issued for them, with larger numbers indicating higher satisfaction. As the Table I shows, all of the Cronbach' $\alpha$ was greater than 0.85 , it proves that the scale has high reliability.

TABLE 1. THE CRONBACH'A OF TALENT POLICY

\begin{tabular}{|l|l|c|}
\hline \multicolumn{1}{|c|}{ Item } & Cronbach' $\boldsymbol{\alpha}$ & Total Cronbach' $\boldsymbol{\alpha}$ \\
\hline Policy content & 0.88 & \\
\hline Policy implementation & 0.87 & \multirow{2}{*}{0.98} \\
\hline Policy effect & 0.83 & \\
\hline $\begin{array}{l}\text { Overall policy satisfacti } \\
\text { on }\end{array}$ & 0.90 & \\
\hline
\end{tabular}

Through the statistics of various indicators, it can be seen that the average value of the overall satisfaction of talents with the talent policy is 3.89 . According to Table II, talents have the highest satisfaction with the policy implementation process, which is 4.21 ; the second is the satisfaction with the policy implementation effect, which is 3.83 ; the talents have relatively low satisfaction with the policy content, which is 3.71 . It can be seen that talents are most satisfied with the policy implementation and least satisfied with the policy content.

TABLE 2. TALENT POLICY ANALYSIS OF THREE DIMENSIONS

\begin{tabular}{|l|l|l|}
\hline \multicolumn{1}{|c|}{ Item } & Mean & SD \\
\hline $\begin{array}{l}\text { Overall policy satisfac } \\
\text { tion }\end{array}$ & 3.89 & 0.72 \\
\hline Policy content & 3.71 & 0.68 \\
\hline $\begin{array}{l}\text { Policy implementatio } \\
\text { n }\end{array}$ & 4.21 & 0.87 \\
\hline Policy effect & 3.83 & 0.81 \\
\hline
\end{tabular}

According to Table III, $62.1 \%$ of talents are satisfied with the content of the policy, $27.3 \%$ are generally satisfied, and $10.8 \%$ are dissatisfied; $85.8 \%$ are satisfied with the satisfaction of the policy implementation process, and $12.2 \%$ are generally satisfied, $2 \%$ are dissatisfied; $66 \%$ of talents are satisfied with the policy effect, $29 \%$ are generally dissatisfied, and $5 \%$ are dissatisfied. It shows that most talents are satisfied with the policy content, policy implementation process, and policy implementation effect. Among them, the talents who are satisfied with the policy implementation process are the most, those who are satisfied with the policy implementation effect are second, and the talents who are satisfied with the policy content are the least.

TABLE 3. TALENT POLICY SATISFACTION DISTRIBUTION

\begin{tabular}{|l|l|l|l|l|l|}
\hline \multirow{2}{*}{ Item } & \multicolumn{5}{|l|}{ Satisfaction score $^{\mathbf{a}}$} \\
\cline { 2 - 6 } & $\mathbf{5}$ & $\mathbf{4}$ & $\mathbf{3}$ & $\mathbf{2}$ & $\mathbf{1}$ \\
\hline Policy content & $0 \%$ & $\begin{array}{l}10 . \\
8 \%\end{array}$ & $\begin{array}{l}27 \\
3 \%\end{array}$ & $\begin{array}{l}42 . \\
1 \%\end{array}$ & $20 \%$ \\
\hline $\begin{array}{l}\text { Policy implementatio } \\
\text { n }\end{array}$ & $0 \%$ & $2 \%$ & $\begin{array}{l}12 \\
2 \%\end{array}$ & $\begin{array}{l}57 \\
5 \%\end{array}$ & $\begin{array}{l}28 \\
3 \%\end{array}$ \\
\hline Policy effect & $0 \%$ & $5 \%$ & $29 \%$ & $48 \%$ & $18 \%$ \\
\hline
\end{tabular}

a. "5" means very satisfied, "4" means satisfied, " 3 " mean $\mathrm{s}$ generally satisfied, " 2 " means not satisfied, " 1 " means very dissatisfied

\subsection{Analysis of talent policy content satisfaction}

The average content satisfaction of talents to the talent policy is 3.71, ranking the lowest among the three dimensions. As shown in Table IV, talents have the highest satisfaction with welfare policy, which is 4.24 ; the second one is talents' satisfaction with life security policy, which is 3.96; the third is talents' satisfaction with career policy, which is 3.35; finally, the talents' satisfaction with social relations is 3.09 . It can be seen that there is a large gap between welfare policy satisfaction and social relations policy satisfaction, indicating that talents are most satisfied with the welfare treatment policy in the various items of the policy content, and satisfaction with life security policy and career policy is second. Most dissatisfied with social relations policy.

TABLE 4. TALENT POLICY CONTENT SATISFACTION ANALYSIS

\begin{tabular}{|l|l|l|}
\hline \multicolumn{1}{|c|}{ Item } & Mean & SD \\
\hline Welfare policy & 4.24 & 0.66 \\
\hline Life security policy & 3.96 & 0.70 \\
\hline Career policy & 3.35 & 0.76 \\
\hline Social relations & 3.09 & 0.86 \\
\hline
\end{tabular}

According to Table V, 89.7\% of the talents are satisfied with the welfare policy, $9.2 \%$ are generally satisfied, and $1.1 \%$ are dissatisfied; $77 \%$ of the talents are satisfied with the life security policy, $21.3 \%$ said they are general satisfied, and $1.7 \%$ said they are not satisfied; $48.3 \%$ of talents expressed satisfaction with career policy, $37.4 \%$ expressed general satisfied, and $14.4 \%$ expressed dissatisfaction; $37.9 \%$ of talents are satisfied with the 
social relations policy, $33.9 \%$ are generally satisfied, and $28.1 \%$ are dissatisfied. It can be seen that talents are highly satisfied with welfare policy and living security policy. The evaluations of career policy and social relations policy are more concentrated on general satisfaction and dissatisfaction, career policy and the social relations policy needs further improvement.

TABLE 5. TALENT POLICY CONTENT SATISFACTION DISTRIBUTION

\begin{tabular}{|l|l|l|l|l|l|}
\hline \multirow{2}{*}{ Item } & \multicolumn{5}{|l}{ Satisfaction score } \\
\cline { 2 - 6 } & $\mathbf{5}$ & $\mathbf{4}$ & $\mathbf{3}$ & $\mathbf{2}$ & $\mathbf{1}$ \\
\hline Welfare policy & $0 \%$ & $1.1 \%$ & $9.2 \%$ & $54.6 \%$ & $35.1 \%$ \\
\hline $\begin{array}{l}\text { Life security po } \\
\text { licy }\end{array}$ & $0 \%$ & $1.7 \%$ & $21.3 \%$ & $56.3 \%$ & $20.7 \%$ \\
\hline Career policy & $0.6 \%$ & $13.8 \%$ & $37.4 \%$ & $46.6 \%$ & $1.7 \%$ \\
\hline Social relations & $1.7 \%$ & $26.4 \%$ & $33.9 \%$ & $36.8 \%$ & $1.1 \%$ \\
\hline
\end{tabular}

\subsection{Analysis of talent policy implementation sati sfaction}

The average value of talent satisfaction with the policy implementation process of talent policy is 4.21 , ranking the highest among the three dimensions. According to Table VI, the talents' satisfaction with the talent' service attitude is 4.21; the second is the talent's satisfaction with the service capability, which is 4.08 ; the third is the talent's satisfaction with the policy publicity, which is 3.80; the satisfaction of the talents with the service procedure is 3.44 . It shows that the talents are most satisfied with the service attitude of the agency in the policy implementation process, the satisfaction with the executive staff's service capability and policy publicity is second, and talents are most dissatisfied with the service procedure.

TABLE 6. TALENT POLICY IMPLEMENTATION SATISFACTION ANALYSIS

\begin{tabular}{|l|l|l|}
\hline \multicolumn{1}{|c|}{ Item } & Mean & SD \\
\hline Policy publicity & 3.80 & 0.74 \\
\hline Service procedure & 3.44 & 0.78 \\
\hline Service attitude & 4.21 & 0.66 \\
\hline Service capability & 4.08 & 0.71 \\
\hline
\end{tabular}

According to Table VII, $68.4 \%$ of the talents are satisfied with the policy publicity, $28.2 \%$ are generally satisfied, $3.4 \%$ are dissatisfied; $48.9 \%$ are satisfied with the service procedure, and $40.8 \%$ are generally satisfied, $10.4 \%$ are dissatisfied; $89.1 \%$ of the talents are satisfied with service attitude, $9.8 \%$ are generally satisfied, $1.1 \%$ are dissatisfied; $82.2 \%$ are satisfied with service capability, and $16.1 \%$ are generally satisfied, $1.7 \%$ are dissatisfied. It can be seen that talents have higher evaluations of service attitudes, service capability, and policy publicity efforts, while evaluations of service procedure are more focused on general satisfaction and dissatisfaction. Therefore, more efforts are needed to improve talents' service procedure.
TABLE 7. TALENT POLICY IMPLEMENTATION SATISFACTION DISTRIBUTION

\begin{tabular}{|l|l|l|l|l|l|}
\hline \multirow{2}{*}{ Item } & \multicolumn{5}{|l}{ Satisfaction score } \\
\cline { 2 - 6 } & $\mathbf{5}$ & $\mathbf{4}$ & $\mathbf{3}$ & $\mathbf{2}$ & $\mathbf{1}$ \\
\hline Policy publicity & $0 \%$ & $3.4 \%$ & $28.2 \%$ & $52.9 \%$ & $15.5 \%$ \\
\hline Service procedure & $0.6 \%$ & $9.8 \%$ & $40.8 \%$ & $42.5 \%$ & $6.3 \%$ \\
\hline Service attitude & $0 \%$ & $1.1 \%$ & $9.8 \%$ & $56.3 \%$ & $32.8 \%$ \\
\hline Service capability & $0 \%$ & $1.7 \%$ & $16.1 \%$ & $54.6 \%$ & $27.6 \%$ \\
\hline
\end{tabular}

\subsection{Analysis of talent policy effect satisfaction}

The average satisfaction of talents with the talent policy effect is 3.83, ranking in the middle of the three dimensions. The results are shown in Table VIII. Talents are highest satisfaction with policy completion, with a score of 4.02; ranking second is their satisfaction with policy awareness, with a score of 3.75 ; ranking third is their satisfaction with policy dependence, with a score of 3.71; The lowest ranked is the policy benefits satisfaction with a score of 3.37. This shows that talents are most satisfied with the policy completion and most dissatisfied with policy benefits.

TABLE 8. TALENT POLICY EFFECT SATISFACTION ANALYSIS

\begin{tabular}{|l|l|l|}
\hline \multicolumn{1}{|c|}{ Item } & Mean & SD \\
\hline Policy awareness & 3.75 & 0.66 \\
\hline Policy benefit & 3.37 & 0.83 \\
\hline Policy dependence & 3.71 & 0.74 \\
\hline Policy completion & 4.02 & 0.67 \\
\hline
\end{tabular}

According to Table IX, $67.2 \%$ of talents are satisfied with policy awareness, $30.5 \%$ are generally satisfied, and $2.3 \%$ are dissatisfied; $46.5 \%$ of talents are satisfied with the benefits of the policy, and $39.7 \%$ are generally satisfied. $13.8 \%$ are dissatisfied; $64.9 \%$ of talents are satisfied with policy dependence, $29.9 \%$ are generally satisfied, and $5.2 \%$ are dissatisfied; $80.7 \%$ of talents are satisfied with the policy completion, and $17.8 \%$ are generally satisfied , $1.4 \%$ are dissatisfied. It can be seen that talents are highly satisfied with policy completion, and the evaluation of policy awareness and policy dependence is average, and the evaluation of the policy benefit is more concentrated on the general satisfaction and dissatisfaction level. Therefore, if the talent policy wants to improve the policy effect, it should pay attention to the expansion of the benefit.

TABLE 9. TALENT POLICY EFFECT SATISFACTION DISTRIBUTION

\begin{tabular}{|l|l|l|l|l|l|}
\hline \multirow{2}{*}{ Item } & \multicolumn{5}{|l|}{ Satisfaction score } \\
\cline { 2 - 6 } & $\mathbf{5}$ & $\mathbf{4}$ & $\mathbf{3}$ & $\mathbf{2}$ & $\boldsymbol{1}$ \\
\hline Policy awareness & $0 \%$ & $2.3 \%$ & $30.5 \%$ & $56.9 \%$ & $10.3 \%$ \\
\hline Policy benefit & $1.7 \%$ & $12.1 \%$ & $39.7 \%$ & $40.8 \%$ & $5.7 \%$ \\
\hline
\end{tabular}




\begin{tabular}{|l|l|l|l|l|l|}
\hline Policy dependence & $0 \%$ & $5.2 \%$ & $29.9 \%$ & $53.4 \%$ & $11.5 \%$ \\
\hline Policy completion & $0 \%$ & $1.4 \%$ & $17.8 \%$ & $58.6 \%$ & $22.1 \%$ \\
\hline
\end{tabular}

\subsection{Factor analysis of talent policy satisfaction}

Since the analysis of the talent policy satisfaction of the above 12 index items is more complicated, this part tends to use factor analysis method to analyze the contribution of the index. In the process of factor analysis, KMO test is to judge whether the data is suitable for factor analysis. The value range of KMO statistics is 0 to 1 . It is generally believed that if $\mathrm{KMO}>0.7$, the effect is better. According to the test, the KMO value in our study is 0.95 , and through the Bartlett Test of Sphericity shows that $\mathrm{X} 2=1460.602$, and the significance level is $0.000<0.05$. These data indicate that factor analysis can be used. According to factor analysis, there are 2 common factors with initial eigenvalues $>1$, and the cumulative contribution rate is $68.45 \%$, as shown in Table $\mathrm{X}$.

TABLE 10. EIGENVALUE ANALYSIS OF TALENT POLICY SATISFACTION

\begin{tabular}{|l|l|l|l|}
\hline Factor & Eigenvalue & \% of Variance & $\begin{array}{l}\text { Cumulative } \\
\text { \% }\end{array}$ \\
\hline F1 & 6.88 & 57.30 & 57.30 \\
\hline F2 & 1.34 & 11.15 & 68.45 \\
\hline
\end{tabular}

According to Table XI, the factor F1 represents the satisfaction of the service attitude, the satisfaction of the Service capability, the satisfaction of welfare policy, the satisfaction of policy completion, the satisfaction of life security policy, and the satisfaction of policy publicity. The factor of service attitude satisfaction is 0.92 , which is the largest among the six items in F1, indicating that this factor has the greatest impact on F1.

Factor F2 includes social relations policy satisfaction, career policy satisfaction, policy benefit satisfaction, service procedure satisfaction, policy awareness satisfaction, and policy dependence satisfaction. Among them, the factor of social relations policy satisfaction is 0.89 , which is the largest among the 6 items in F2, indicating that social relations policy satisfaction has the greatest impact on F2. The above factor analysis shows that the greatest impact on talent policy satisfaction is service attitude satisfaction and social relations policy satisfaction.

TABLE 11. FACTOR ANALYSIS OF TALENT POLICY SATISFACTION

\begin{tabular}{|l|l|c|}
\hline \multirow{2}{*}{\multicolumn{1}{|c|}{ Item }} & \multicolumn{2}{c|}{ Component } \\
\cline { 2 - 3 } & \multicolumn{1}{c|}{$\boldsymbol{2}$} \\
\hline Service attitude & 0.92 & 0.21 \\
\hline Service capability & 0.84 & 0.26 \\
\hline Welfare policy & 0.83 & 0.23 \\
\hline Policy completion & 0.79 & 0.42 \\
\hline Life security policy & 0.64 & 0.46 \\
\hline
\end{tabular}

\begin{tabular}{|l|l|l|}
\hline Policy publicity & 0.60 & 0.57 \\
\hline Social relations & 0.17 & 0.89 \\
\hline Career policy & 0.30 & 0.82 \\
\hline Policy benefit & 0.27 & 0.76 \\
\hline Service procedure & 0.29 & 0.73 \\
\hline Policy awareness & 0.54 & 0.56 \\
\hline Policy dependence & 0.24 & 0.55 \\
\hline
\end{tabular}

\section{CONCLUSION}

Based on the relevant theories of satisfaction measurement and combined with the current world practice of talent policy, the study constructs a satisfaction model suitable for talent policy. We collected data of the talents serving the development of China-ASEAN through an online survey and made an accurate analysis of it. Now we can arrive at the following conclusions. First, from the overall level of satisfaction, China-ASEAN talents are generally satisfied with the current talent policy. Second, the talents are most satisfied with the policy implementation process, which means that the talent policy has a strong executive power and the talent service is considerate and friendly; talents are relatively least satisfied with the content of the policy, which indicates that the formulation of the talent policy should have a deep understanding of the talents' needs. Third, the greatest impact on overall policy satisfaction are the attitude of talent service and the satisfaction of social relations policy. It shows that the satisfaction of talents has a strong perceptual color. From the perspective of emotion, we should serve talents and help them build a mature society.

The China-ASEAN talent policy now is inherently faced with problems such as insufficient international talent reserves, lack of attention to talent needs, serious brain drain problems, and loss of competitiveness of talents. To solve these problems, we should return to the research conclusions of this article. First, in order to improve the satisfaction of talents with the content of the China-ASEAN talent policy, an environment that respects and cares for talents should be created. The government should improve and implement policy to ensure the life of talents, such as talents' health, employment of talents' spouses, education of talent's children, and settlement of talent's family members, focusing on strengthening care and assistance for talents' marriage and love, parent-child relationship, family health and other family pressures. At the same time, the government should pay attention to the establishment of an Internet information communication platform, promote work and life communication between talents, optimize the working environment of talents, provide relevant funding, and provide a platform for the development of talents. Secondly, in order to improve the satisfaction of the implementation of the China-ASEAN talent policy, a sound talent service mechanism should be established to improve the talent service level. In particular, the relevant procedures should be simplified through the Internet platform, and the Internet platform 
should be used to provide information consultation and service handling. Finally, in order to improve the satisfaction of the implementation of the China-ASEAN talent policy, it is necessary to maximize the coverage of the talent policy, increase government support, promote policy publicity, and strengthen the government, enterprises, and society's immediate evaluation of the talent policy.

\section{REFERENCES}

1. R. N. Cardozo, "An experimental study of customer effort, expectation, and Satisfaction," Journal of Marketing Research, vol. 2, pp. 244-249, 1965.

2. R. L. Oliver, "Customer delight foundations, fingdings and consequences of satisfacation decision," Journal of Retailing, vol. 73, pp. 311-339, 1997.

3. M. D. Johnson, A. Gustafsson, T. W. Andreassen, L. Line and C. Jaesung, "The evolution and future of national Customer Satisfaction Index Models," Journal of Economic Psychology, vol. 22, pp. 217245, 2001.

4. A. S. Dick and K. Basu, "Customer loyalty: toward an integrated conceptual framework," Journal of the Academy of Marketing Science, vol. 22, pp. 99-113, 1994.

5. P. Holland, C. Sheehan and H. Cieri, "Attracting and retaining talent: exploring human resources development trends in Australia," Human Resource Development International, vol. 10, pp. 247-262, 2007.

6. C. M. Vazzana and J. R. Polloshka, "Appalachia has got talent, but why does it flow away? a study on the determinants of brain drain from rural USA," Economic Development Quarterly, vol. 33, pp. 245250, 2019.

7. E. J. Mccann, "Best places: interurban competition, quality of life and popular media discourse," Urban Studies, vol. 41, pp. 1909-1929, 2004.

8. O. Chantal and D. P. Yvonne, "The role of psychological ownership in retaining talent: a systematic literature review," SA Journal of Human Resource Management, vol. 10, pp. 202-205, 2012.

9. Douglass, A. John, Edelstein and Richard, "Whither the global talent pool," Change the Magazine of Higher Learning, vol. 41, pp. 36-44, 2009.

10. W. S. Harvey, "British and Indian scientists moving to the U.S," Work \& Occupations, vol. 38, pp. 243247, 2011. 